\title{
Original
}

\section{Efficacy, safety, and pharmacokinetics of sustained-release lanreotide (lanreotide Autogel) in Japanese patients with acromegaly or pituitary gigantism}

\author{
Akira Shimatsu $^{1)}$, Akira Teramoto ${ }^{2), 3)}$, Naomi Hizuka ${ }^{4)}$, Kazuo Kitai ${ }^{5)}$, Joaquim Ramis ${ }^{6)}$ and \\ Kazuo Chihara ${ }^{7)}$ \\ 1) Clinical Research Institute, National Hospital Organization Kyoto Medical Center, Kyoto 612-8555, Japan \\ 2) Department of Neurosurgery, Nippon Medical School, Tokyo 113-8603, Japan \\ 3) Tokyo Rosai Hospital, Tokyo 143-0013, Japan \\ 4) Department of Medicine II, Tokyo Women's Medical University, Tokyo 162-8666, Japan \\ 5) Teijin Pharma Limited, Tokyo 100-8585, Japan \\ 6) Ipsen Innovation, Les Ulis 91940 , France \\ 7) Hyogo Prefectural Kakogawa Medical Center, Kakogawa 675-8555, Japan
}

\begin{abstract}
The somatostatin analog lanreotide Autogel has proven to be efficacious for treating acromegaly in international studies and in clinical practices around the world. However, its efficacy in Japanese patients has not been extensively evaluated. We examined the dose-response relationship and long-term efficacy and safety in Japanese patients with acromegaly or pituitary gigantism. In an open-label, parallel-group, dose-response study, 32 patients (29 with acromegaly, 3 with pituitary gigantism) received 5 injections of 60,90 , or $120 \mathrm{mg}$ of lanreotide Autogel over 24 weeks. Four weeks after the first injection, $41 \%$ of patients achieved serum GH level of $<2.5 \mathrm{ng} / \mathrm{mL}$ and insulin-like growth factor-I (IGF-I) level was normalized in 31\%. Values at Week 24 were 53\% for GH and $44 \%$ for IGF-I. Dose-dependent decreases in serum GH and IGF-I levels were observed with dose-related changes in pharmacokinetic parameters. In an open-label, long-term study, 32 patients (30 with acromegaly, 2 with pituitary gigantism) received lanreotide Autogel once every 4 weeks for a total of 13 injections. Dosing was initiated with $90 \mathrm{mg}$ and adjusted according to clinical responses at Weeks 16 and/or 32. At Week 52, $47 \%$ of patients had serum GH levels of $<2.5 \mathrm{ng} / \mathrm{mL}$ and $53 \%$ had normalized IGF-I level. In both studies, acromegaly symptoms improved and treatment was generally well tolerated although gastrointestinal symptoms and injection site induration were reported. In conclusion, lanreotide Autogel provided early and sustained control of elevated GH and IGF-I levels, improved acromegaly symptoms, and was well tolerated in Japanese patients with acromegaly or pituitary gigantism.
\end{abstract}

Key words: Acromegaly, Lanreotide Autogel, Growth hormone, Insulin-like growth factor-I, Somatostatin analog

ACROMEGALY is caused by excessive secretion of $\mathrm{GH}$, usually because of a pituitary adenoma, which in turn mediates increases in insulin-like growth factor-I (IGF-I) levels. These endocrine disturbances lead to headache, excessive sweating and acral enlargement [1]. Endocrine disturbances are associated with many clinically significant complications, particularly hypertension, diabetes mellitus, and cardiac diseases [2].

Submitted Nov. 12, 2012; Accepted Dec. 27, 2012 as EJ12-0417 Released online in J-STAGE as advance publication Jan. 19, 2013 Correspondence to: Dr. Akira Shimatsu, Clinical Research Institute, National Hospital Organization Kyoto Medical Center, 1-1 Mukaihata-cho, Fukakusa, Fushimi-ku, Kyoto 612-8555, Japan. E-mail: ashimats@kyotolan.hosp.go.jp
Cardiovascular diseases and malignancy are the most serious complications, leading to morbidity and mortality rates that are more than double the corresponding rates in the general population [3-6]. Pituitary gigantism is also caused by excessive GH secretion, although this occurs in adolescents prior to epiphyseal closure. A key objective of treatment in both cases is to normalize serum GH and IGF-I levels. Transsphenoidal surgery is generally recommended as the first-line treatment for patients with microadenomas, or patients with macroadenomas that are either associated with local mass effects or are enclosed. Depending on the experience of the neurosurgeon and tumor size, surgery offers a moderate-to-high likelihood of a cure for 
these patients. For patients that have inoperable adenomas or for patients with a residual tumor or tumor recurrence, the alternative treatment options are medical treatment, commonly with a somatostatin analog (SSA), radiotherapy, or both [7]. In some patients, first-line pharmacotherapy with SSA followed by surgery may be appropriate [7]. Currently, lanreotide and octreotide are 2 SSAs available for the management of acromegaly in the U.S., Europe, and many other countries around the world.

Lanreotide Autogel (marketed as Somatuline ${ }^{\circledR}$ Depot in the U.S. and Somatuline ${ }^{\circledR}$ Autogel ${ }^{\circledR}$ in most other countries) is a sustained-release, supersaturated formulation of the SSA lanreotide. The drug is supplied in ready-to-use, pre-filled syringes for subcutaneous administration, typically every 4 weeks. The drug is slowly released over a period of at least 1 month following administration from a depot formed at the injection site [8]. In international studies, this treatment has demonstrated good efficacy and safety in the medical management of acromegaly [9-13], with an efficacy and safety profile that is similar to that of octreotide LAR [14-16]. Lanreotide Autogel has been used for a number of years in clinics around the world. However, it has not been extensively evaluated in Japanese patients. Here, we report outcomes from 2 clinical trials with lanreotide Autogel in Japanese patients with acromegaly or pituitary gigantism. One trial was an open-label, dose-response phase II study and the second was a 52-week, open-label phase III study in which efficacy and safety were evaluated.

\section{Materials and Methods}

\section{Patients}

Inclusion and exclusion criteria for selecting patients were almost identical in the dose-response study and long-term studies. Japanese patients aged 18 years or more with active acromegaly or pituitary gigantism were included. GH inclusion criteria were set by reference to the international study [9] (dose-response study) or the Japanese guideline [17] (long-term study). Patients who had never received treatment with SSAs or dopamine agonists, or who had stopped taking these medications $>12$ weeks before entering the study were eligible if their mean serum GH levels at screening were $>2.8 \mathrm{ng} / \mathrm{mL}$ (dose-response study) or $>2.5 \mathrm{ng} / \mathrm{mL}$ (long-term study). In the dose-response study, patients receiving an SSA or dopamine agonist immediately prior to enrollment underwent treatment washout (1-8 weeks) and these patients were eligible for the study if their post-washout mean $\mathrm{GH}$ levels were $>1.7 \mathrm{ng} /$ $\mathrm{mL}$ and increased by at least 2 fold over screening levels. In the long-term study, patients receiving an SSA, dopamine agonist or $\mathrm{GH}$ receptor antagonist immediately prior to enrollment underwent treatment washout (1-8 weeks) and these patients were eligible for the study if their post-washout mean GH levels were $>2.5$ $\mathrm{ng} / \mathrm{mL}$. In both studies, if $\mathrm{GH}$ inclusion criteria were not met at the first post-washout assessment, a second assessment was performed 2-6 weeks later. Patients were excluded if they had undergone radiotherapy for acromegaly within the preceding 12 months or pituitary surgery within 12 weeks prior to enrollment. Patients who were pregnant or breastfeeding, or who had hepatic or renal impairment or severe heart disease were also excluded.

\section{Study design, interventions and assessments \\ Phase II dose-response study}

This clinical study was started in 2007 as a multicenter, open-label, randomized, parallel-group, phase II study conducted at 24 hospitals. The study comprised an observation period (2-12 weeks, depending on the presence or absence and nature of prior treatment), a single-dosing period ( 8 weeks), and a repeat-dosing period (16 weeks) (Fig. 1A). Patients were randomly assigned and equally distributed into $60-\mathrm{mg}, 90-\mathrm{mg}$, or 120 -mg dosing groups. Treatment was administered deep subcutaneously in the buttocks at Weeks $0,8,12$, 16 , and 20 using the injection device available at the time of the study, which comprised a ready-to-use, prefilled syringe with either a $1.2-\mathrm{mm}(60-\mathrm{mg}$ and $90-\mathrm{mg}$ doses) or 1.4-mm diameter needle (120-mg doses).

Mean GH levels were determined from a series of 4 serum samples obtained at 1-hour intervals during the observation period. Samples were collected before the first injection (Week 0), and before the injections at Weeks 4 and 24. A single serum sample was obtained for the assessment of IGF-I levels at each of the 4-weekly visits and before injection. GH and IGF-I levels were measured centrally using immunoradiometric assays (GH Kit Dai-ichi, with standards calibrated against recombinant GH (WHO 98/574) and IGF-I IRMA Dai-ichi; TFB Inc., Japan). Serum samples obtained at each visit were assayed for non-specific binding (NSB) to lanreotide. If NSB was $\geq 7.1 \%$, the samples were subjected to a second assay to deter- 

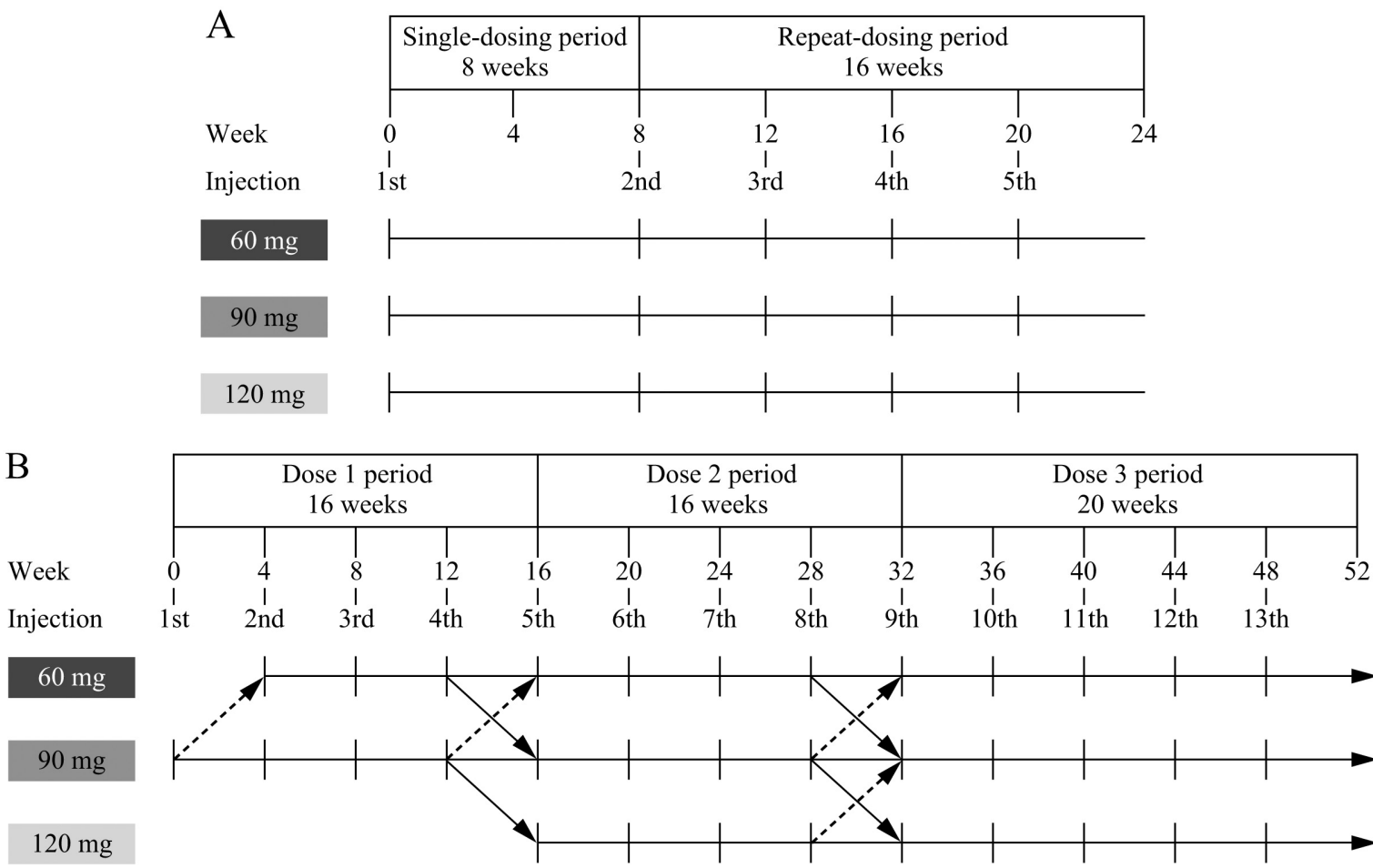

Fig. 1 Study design for the dose-response (panel A) and long-term studies (panel B)

In panel B, thin solid arrows indicate increased dose, heavy solid arrows indicate maintained dose, and dashed arrows indicate decreased dose.

mine the immunodepression (ID) rate for NSB. If the ID rate in the second assay was $\geq 30 \%$, lanreotide antibodies were considered present. Patients were assessed for symptoms of acromegaly at each visit.

Safety was assessed by collecting information on adverse events (AEs) at every visit. Vital signs and laboratory assessments (blood chemistry, hematological, and endocrinological) were also performed. Electrocardiograms (ECG), abdominal ultrasonography of the gall bladder, and magnetic resonance imaging (MRI) or computed tomography (CT) scans of the head were performed. MRI or CT findings were assessed centrally (by AT: Nippon Medical School) in accordance with a separate pre-specified protocol. Sagittal and coronal gadolinium-enhanced spin-echo $\mathrm{T}_{1}$ - or $\mathrm{T}_{2}$-weighted MR images (at 1.0T or higher) were obtained. CT was performed in horizontal and coronal planes. Tumor size was assessed based on the anteroposterior diameter, right-to-left diameter, and height of the tumor with considering for the clinical findings of the tumor.

\section{Phase III long-term study}

This study was initiated in 2009 as an open-label, dose-adjustment, long-term treatment, phase III study conducted at 25 hospitals in Japan. The study comprised a pre-treatment observation period (2-22 weeks), followed by a "dose 1 treatment period" (16 weeks), a "dose 2 treatment period" (16 weeks), and a "dose 3 treatment period" (20 weeks) (Fig. 1B). Lanreotide Autogel treatment was initiated with a 90-mg dose, injected deep subcutaneously in the buttocks once every 4 weeks. Doses were titrated upwards in 30-mg increments at Weeks 16 and/or 32 unless mean serum GH was $<1 \mathrm{ng} / \mathrm{mL}$, serum IGF-I was within the ageand gender-adjusted reference range for Japanese population [18], and symptoms indicative of clinical activity had been absent at the previous assessment. Dose was reduced by a 30-mg step if at any point in the study serum IGF-I levels had fallen below the lower limit (median $-2 \times$ standard deviation [SD]) of the age- and gender-adjusted reference range for the Japanese population. An investigator would also consider dose reduction by a 30-mg step if a clinically significant adverse drug reaction occurred. Treatment was administered with the recently available lanreotide Autogel injection device. This is a ready-to-use, pre-filled syringe similar to the device used in the dose-response study, but 
with a 1.2-mm diameter needle available for all doses, and an automatic needle safety guard.

Similar to the dose-response study, mean GH and IGF-I levels were measured at Weeks 0, 4, 12, 28, and 52. Acromegaly symptoms were assessed at Weeks 0 , $4,8,12,28$, and 52 . Ring size on the same finger of the non-dominant hand was measured using a measurement device according to a separate pre-specified protocol at Weeks $0,4,8,12,28$, and 52. Anti-lanreotide antibody and safety evaluations were performed in a similar manner as the dose-response study (described above).

\section{Ethical considerations}

Both studies were conducted in accordance with the principles of the Declaration of Helsinki and the laws and regulations of Japan, whichever afforded the greater protection to the individual and were approved by Institutional Review Boards. The investigators adhered to Good Clinical Practice Guidelines and patients provided written, informed consent before entering the study.

\section{Statistical analyses}

Descriptive statistical analyses were performed to provide means $\pm \mathrm{SD}$ for data presented in this report, including GH and IGF-I levels. SD for IGF-I scores were calculated according to the age- and gender-adjusted reference ranges in the Japanese population. Two-sided 95\% confidence intervals (CI) were calculated for the proportions of patients achieving biochemical control. The principal analysis set for efficacy and pharmacokinetics (PK) evaluations was the full analysis set (FAS). The FAS was defined as randomized patients exposed to at least 1 dose of trial medication and with at least one post-baseline efficacy or PK assessment. Safety analyses were conducted for all randomized patients exposed to at least 1 dose of trial medication. The data were analyzed using SAS version 9.1 (SAS Institute, Cary, NC, USA). PK parameters were calculated using WinNonlin Professional version 5.2 (Pharsight Corporation, Mountain View, CA, USA).

\section{Results}

\section{Phase II dose-response study 1) Patients}

A total of 57 patients were screened and 33 were enrolled. Thirty-two patients received the study drug and completed the study. No patients were withdrawn.
One enrolled patient was determined by the investigator to be ineligible to receive the study drug, following the discovery of an arrhythmia (extrasystoles) in his ECG at Week 0. Twenty-nine patients $(91 \%)$ had been diagnosed with acromegaly and three $(9 \%)$ with pituitary gigantism. Nineteen patients $(59 \%)$ were either treatment-naive or had not been treated within the previous 12 weeks.

Baseline characteristics and pre-treatment status were similar among the 3 dose groups, one exception being the mean disease duration (60-mg group, 4.5 years; $90-\mathrm{mg}$ group, 11.3 years; $120-\mathrm{mg}$ group, 9.3 years) (Table 1).

\section{2) Efficacy}

\section{GH and IGF-I levels}

Overall, mean $( \pm \mathrm{SD})$ serum $\mathrm{GH}$ levels decreased over time, from $16.5( \pm 24.5) \mathrm{ng} / \mathrm{mL}$ on the day of enrollment to $5.8( \pm 9.2) \mathrm{ng} / \mathrm{mL}$ at Week 4 (4 weeks after the first injection), and to $3.9( \pm 4.4) \mathrm{ng} / \mathrm{mL}$ at Week 24 (4 weeks after the fifth injection). Mean $( \pm$ SD) serum IGF-I levels also decreased over time, from $566.1( \pm 197.8) \mathrm{ng} / \mathrm{mL}$ on the day of enrollment to $361.0( \pm 186.9) \mathrm{ng} / \mathrm{mL}$ at Week 4 , and to $321.2( \pm 188.2)$ $\mathrm{ng} / \mathrm{mL}$ at Week 24.

The proportion of patients with a mean GH level that had decreased $>50 \%$ (compared to baseline) at Week 4 was 66\% (95\% CI: 47-81\%, 21/32 patients) for all dose groups (data were pooled from all groups). This proportion increased as the dose increased (60-mg group, 55\%, 6/11 patients; 90 -mg group, $60 \%$, 6/10 patients; 120 -mg group, $82 \%, 9 / 11$ patients). The proportions were higher at Week 24 compared to Week 4 (Week 24: pooled data from all dose groups, $84 \%, 95 \%$ CI: $67-95 \%, 27 / 32$ patients; $60-\mathrm{mg}$ group, $64 \%, 7 / 11$ patients; 90-mg group, 90\%, 9/10 patients; $120-\mathrm{mg}$ group, $100 \%, 11 / 11$ patients).

The overall proportion of patients with mean serum GH levels $<2.5 \mathrm{ng} / \mathrm{mL}$ or normalized serum IGF-I levels increased between Weeks 4 and 24 (GH, 41\%, 95\% CI: $24-59 \%, 13 / 32$ patients and 53\%, 95\% CI: $35-71 \%$, $17 / 32$ patients, respectively; IGF-I, $31 \%$, 95\% CI: $16-50 \%, 10 / 32$ patients, and $44 \%, 95 \%$ CI: $26-62 \%$, $14 / 32$ patients, respectively). The proportions of patients with both mean serum GH levels $<2.5 \mathrm{ng} / \mathrm{mL}$ and normalized serum IGF-I levels also increased over time (Week 4, 25\%, 95\% CI: 12-43\%, 8/32 patients; Week 24, 41\%, 95\% CI: 24-59\%, 13/32 patients) (Fig. 2). 
Table 1 Baseline demographic and disease characteristics of patients in the dose-response and long-term studies

\begin{tabular}{|c|c|c|c|c|c|c|}
\hline & \multicolumn{4}{|c|}{ Dose-response study } & \multirow{2}{*}{$\begin{array}{c}\text { Long-term study } \\
\text { All } \\
N=32 \\
\end{array}$} \\
\hline & & $\begin{array}{r}60 \mathrm{mg} \\
\mathrm{N}=11\end{array}$ & $\begin{array}{l}90 \mathrm{mg} \\
\mathrm{N}=10\end{array}$ & $\begin{array}{l}120 \mathrm{mg} \\
\mathrm{N}=11\end{array}$ & $\begin{array}{c}\text { All } \\
\mathrm{N}=32\end{array}$ & \\
\hline \multirow{3}{*}{$\begin{array}{l}\text { Age } \\
\text { (years) }\end{array}$} & $\mathrm{N}$ & 11 & 10 & 11 & 32 & 32 \\
\hline & Mean & 47.0 & 47.7 & 46.5 & 47.0 & 47.0 \\
\hline & $\mathrm{SD}$ & 16.8 & 17.5 & 15.2 & 15.9 & 13.4 \\
\hline \multirow{3}{*}{$\begin{array}{l}\text { Height } \\
(\mathrm{cm})\end{array}$} & $\mathrm{N}$ & 11 & 10 & 11 & 32 & 32 \\
\hline & Mean & 167.0 & 161.3 & 169.4 & 166.0 & 166.7 \\
\hline & SD & 12.6 & 6.6 & 16.3 & 12.7 & 11.5 \\
\hline \multirow{3}{*}{$\begin{array}{l}\text { Body weight } \\
\text { (kg) }\end{array}$} & $\mathrm{N}$ & 11 & 10 & 11 & 32 & 32 \\
\hline & Mean & 71.4 & 71.7 & 71.0 & 71.4 & 75.2 \\
\hline & SD & 18.1 & 6.2 & 13.4 & 13.2 & 16.2 \\
\hline \multirow{2}{*}{$\begin{array}{l}\text { Diagnosis } \\
\mathrm{n}(\%)\end{array}$} & Acromegaly & 9 & 10 & 10 & $29(90.6)$ & $30(93.8)$ \\
\hline & Pituitary gigantism & 2 & 0 & 1 & $3(9.4)$ & $2(6.3)$ \\
\hline \multirow{3}{*}{$\begin{array}{l}\text { Duration of acromegaly } \\
\text { since diagnosis } \\
\text { (years) }\end{array}$} & $\mathrm{N}$ & 11 & 10 & 11 & 32 & 32 \\
\hline & Mean & 4.5 & 11.3 & 9.3 & 8.3 & 7.7 \\
\hline & $\mathrm{SD}$ & 4.6 & 13.2 & 8.7 & 9.5 & 7.7 \\
\hline $\begin{array}{l}\text { Surgery } \\
\mathrm{n}(\%)\end{array}$ & Yes & 8 & 9 & 9 & $26(81.3)$ & $27(84.4)$ \\
\hline $\begin{array}{l}\text { Radiation therapy } \\
\mathrm{n}(\%)\end{array}$ & Yes & 1 & 1 & 2 & $4(12.5)$ & $6(18.8)$ \\
\hline \multirow{4}{*}{$\begin{array}{l}\text { Previous drug therapy } \\
\mathrm{n}(\%)\end{array}$} & Yes & 4 & 5 & 4 & $13(40.6)$ & $20(62.5)$ \\
\hline & Prolonged-release SSA & 1 & 2 & 4 & 7 (21.9) & $5(15.6)$ \\
\hline & Short acting SSA & 1 & 0 & 0 & $1(3.1)$ & $1(3.1)$ \\
\hline & Dopamine agonist & 2 & 3 & 0 & $5(15.6)$ & $15(46.9)$ \\
\hline \multirow{3}{*}{$\begin{array}{l}\mathrm{GH} \\
(\mathrm{ng} / \mathrm{mL})\end{array}$} & $\mathrm{N}$ & 11 & 10 & 11 & 32 & 32 \\
\hline & Mean & 11.8 & 10.8 & 26.4 & 16.5 & 10.2 \\
\hline & SD & 11.4 & 10.0 & 38.5 & 24.5 & 10.5 \\
\hline \multirow{3}{*}{$\begin{array}{l}\text { IGF-I } \\
(\mathrm{ng} / \mathrm{mL})\end{array}$} & $\mathrm{N}$ & 11 & 10 & 11 & 32 & 32 \\
\hline & Mean & 626.0 & 553.2 & 518.0 & 566.1 & 549.4 \\
\hline & $\mathrm{SD}$ & 218.2 & 152.5 & 214.7 & 197.8 & 263.8 \\
\hline
\end{tabular}

SSA, somatostatin analog

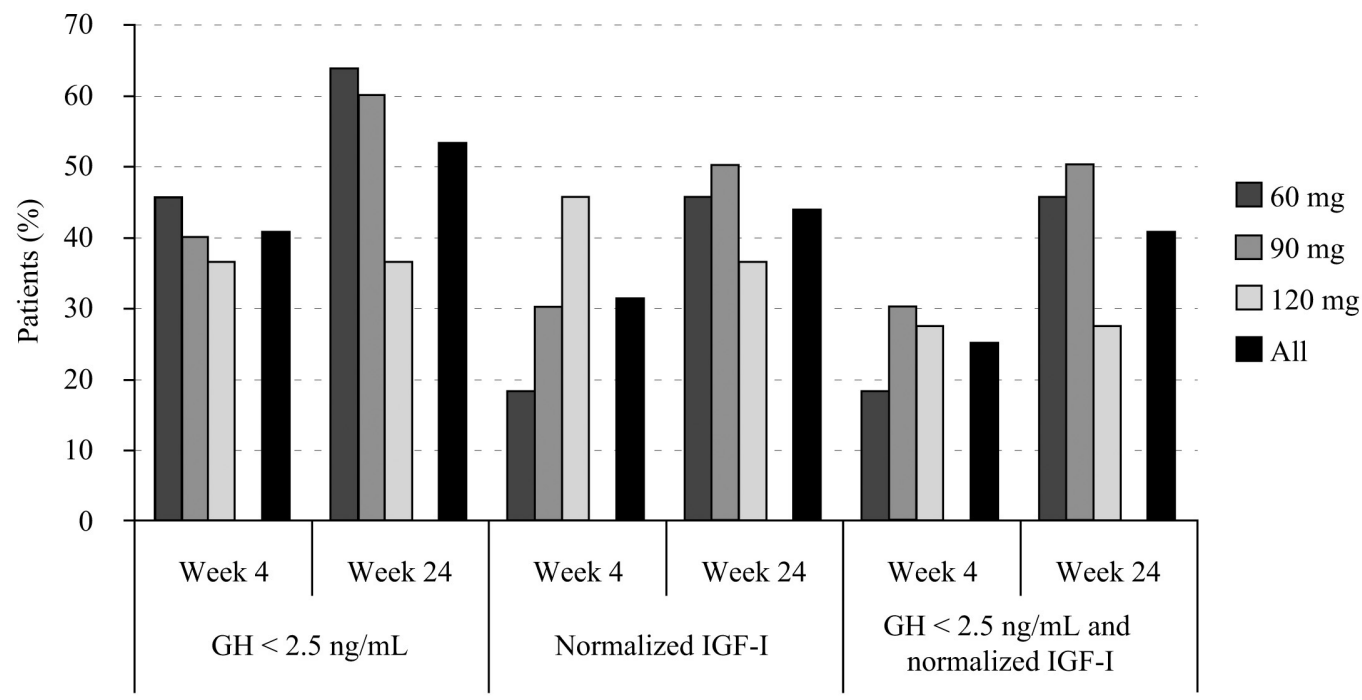

Fig. 2 Proportion of patients with control of GH and IGF-I at Week 4 and 24 (4 weeks after the first and fifth injections, respectively) in the dose-response study IGF-I, insulin-like growth factor-I 

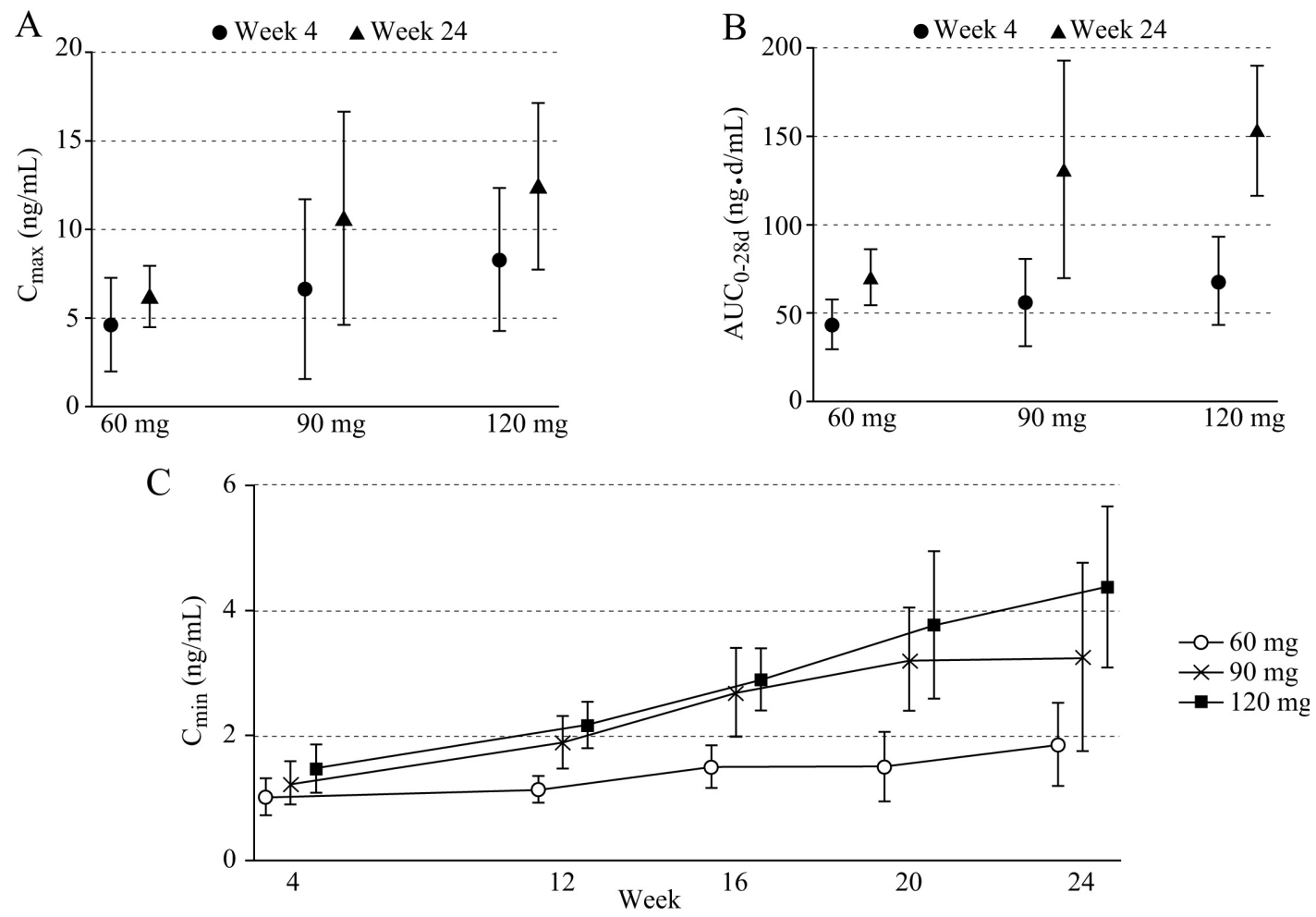

Fig. 3 PK parameters of serum lanreotide in the dose-response study

(A) $\mathrm{C}_{\max }$ and (B) $\mathrm{AUC}_{0-28 \mathrm{~d}}$ data from Week 4 and 24 (4 weeks after the first and fifth injections, respectively). (C) Mean ( \pm SD) $\mathrm{C}_{\min }$ data are from Week 4, 12, 16, 20 and 24 (4 weeks after the first, second, third, fourth and fifth injection, respectively).

$\mathrm{C}_{\max }$, maximum concentration; $\mathrm{C}_{\mathrm{min}}$, minimum concentration; $\mathrm{AUC}_{0-28 \mathrm{~d}}$, area under the concentration-time curve

Data are presented as mean $\pm \mathrm{SD}$.

\section{Clinical symptoms}

Compared to baseline descriptions, clinical symptoms of acromegaly improved or were stable in most patients throughout the study. Seventy percent of patients (14/20) with hyperhidrosis, $80 \%$ of patients $(20 / 25)$ with swelling of distal extremities, and $88 \%$ of patients $(7 / 8)$ with paresthesia reported improved symptoms compared to symptoms on the first day of injection.

\section{Pituitary tumor size}

Tumor size was reduced in 10 patients at Week 24 ( $\geq 80 \%$ reduction in 1 patient; $\geq 50 \%$ to $<80 \%$ reduction in 5 patients, and $\geq 30 \%$ to $<50 \%$ reduction in 4 patients). In 9 patients, tumor size did not change, and in the remaining 13 patients, tumor size could not be evaluated.

\section{3) Safety}

A total of 230 AEs were recorded among all 32 patients (60-mg group, 89 events; 90-mg group, 76 events; 120 -mg group, 65 events). There were no significant differences in the incidence and severity of AEs among the dose groups. The most commonly reported AEs were: injection site induration $(53 \%, 17$ patients), pale feces
(41\%, 13 patients), diarrhea (34\%, 11 patients), injection site pain, cholelithiasis and nasopharyngitis $(16 \%, 5$ patients in each case), abdominal distension, abdominal pain, and nausea (13\%, 4 patients in each case). None of the patients withdrew from the study. One patient (3\%) in the 90-mg group experienced 2 serious AEs, retinal hemorrhage and edema. These serious AEs were not considered as related to the study medication by the investigator. One patient (3\%) tested positive for anti-lanreotide antibodies (ID rate, 38-45\%). There were no clinically meaningful changes in other safety assessments.

\section{4) Pharmacokinetics (PK)}

The mean maximum and minimum concentrations $\left(\mathrm{C}_{\max }\right.$ and $\mathrm{C}_{\min }$, respectively) and area under the concentration-time curve $\left(\mathrm{AUC}_{0-28 \mathrm{~d}}\right)$ values for serum lanreotide increased with the increase in dosage (Fig. 3). Serum lanreotide concentrations reached $\mathrm{a}_{\max }$ of 4.58 , 6.57 , and $8.25 \mathrm{ng} / \mathrm{mL} 5$ to 7 hours after the first injection in the 60-mg, 90-mg, and 120-mg groups, respectively. $\mathrm{C}_{\text {min }}$ values 4 weeks after the first injection were: 1.01 , 1.23 , and $1.46 \mathrm{ng} / \mathrm{mL}$ in the $60-\mathrm{mg}, 90-\mathrm{mg}$, and $120-\mathrm{mg}$ 


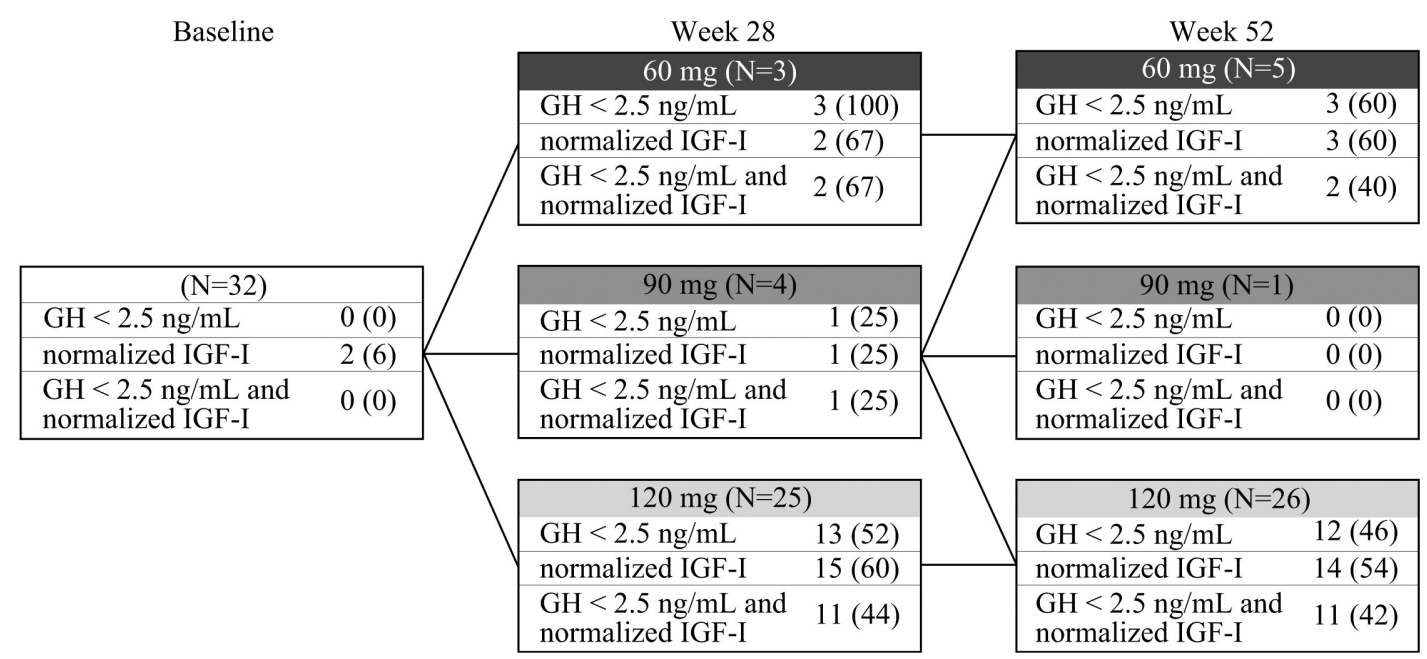

Fig. 4 Proportion of patients with control of GH and IGF-I levels at Week 28 and Week 52 in the long-term study Data presented include those patients who withdrew before Week 28 and/or 52. Parentheses indicate the percentage of patients. IGF-I, insulin-like growth factor-I

groups, respectively. Serum lanreotide concentrations increased with repeated injection, and reached a steady state after the fourth injection.

\section{Phase III long-term study 1) Patients}

A total of 40 patients were screened, 32 were enrolled and received the study drug, and 30 completed the study. Only 8 patients were recruited from the doseresponse study. Of the 32 patients, 2 patients $(6 \%)$ were withdrawn, one due to an AE (abnormal hepatic function) and another due to exacerbation of the underlying disease or absence of response to the study drug (pituitary enlargement). Baseline characteristics and pretreatment status are shown in Table 1. Thirty patients (94\%) were diagnosed with acromegaly and 2 patients $(6 \%)$ were diagnosed with pituitary gigantism. Twelve patients $(38 \%)$ were either treatment-naive or had not been treated within the previous 12 weeks.

\section{2) Efficacy}

\section{GH and IGF-I levels}

Mean $( \pm \mathrm{SD})$ serum GH levels decreased over time from $10.2( \pm 10.5) \mathrm{ng} / \mathrm{mL}$ on the day of the first injection (Week 0) to $3.8( \pm 5.3) \mathrm{ng} / \mathrm{mL}$ at Week 28. GH levels remained stable through to Week $52(3.4( \pm 3.2) \mathrm{ng} / \mathrm{mL})$. The proportion of patients exhibiting a decrease in mean serum GH levels $>50 \%$ (compared to baseline values) at Week 52 was $66 \%$ (95\% CI: 47-81\%, 21/32 patients). The proportion of patients with mean serum GH levels
$<2.5 \mathrm{ng} / \mathrm{mL}$ and $<1 \mathrm{ng} / \mathrm{mL}$ at Week 52 were $47 \%(95 \%$ CI: $29-65 \%, 15 / 32$ patients) (Fig. 4) and 3\% (95\% CI: $0-16 \%, 1 / 32$ patients), respectively. Changes in serum GH levels in individual patients are shown in Fig. 5A.

Mean $( \pm \mathrm{SD})$ serum IGF-I level decreased up to Week 28, and remained stable thereafter (Week 0 , $549.4( \pm 263.8) \mathrm{ng} / \mathrm{mL}$; Week 28, $268.0( \pm 158.6) \mathrm{ng} /$ $\mathrm{mL}$; Week 52, $270.8( \pm 176.3) \mathrm{ng} / \mathrm{mL})$. The proportion of patients with normalized serum IGF-I levels was 53\% (95\% CI: 35-71\%, 17/32 patients) at Week 52 (Fig. 4). Mean ( \pm SD) IGF-I SD scores also decreased up to Week 28 and remained stable thereafter (Week 0, $6.0( \pm 2.8)$; Week 28, $2.0( \pm 2.5)$; Week 52, $2.1( \pm 2.4)$ ). Changes in serum IGF-I SD scores for individual patients are shown in Fig. 5B.

The proportion of patients with both mean serum GH levels $<2.5 \mathrm{ng} / \mathrm{mL}$ and normalized serum IGF-I levels at Week 52 was $41 \%$ (95\% CI: $24-59 \%, 13 / 32$ patients) (Fig. 4).

Clinical symptoms

Compared with baseline, clinical symptoms of acromegaly improved or were stable in most patients throughout the study. Specifically, symptoms improved in $72 \%$ of patients $(13 / 18)$ with hyperhidrosis, $64 \%$ $(9 / 14)$ with fatigue, $64 \%(16 / 25)$ with swelling of distal extremities, and $63 \%$ of patients (5/8) with arthralgia.

\section{Ring size}

A time-dependent decrease in the ring size was observed, with a mean $( \pm \mathrm{SD})$ change from baseline in scales of $3.6( \pm 4.3)$ at Week 52 (Fig. 6). A total of $90 \%$ 

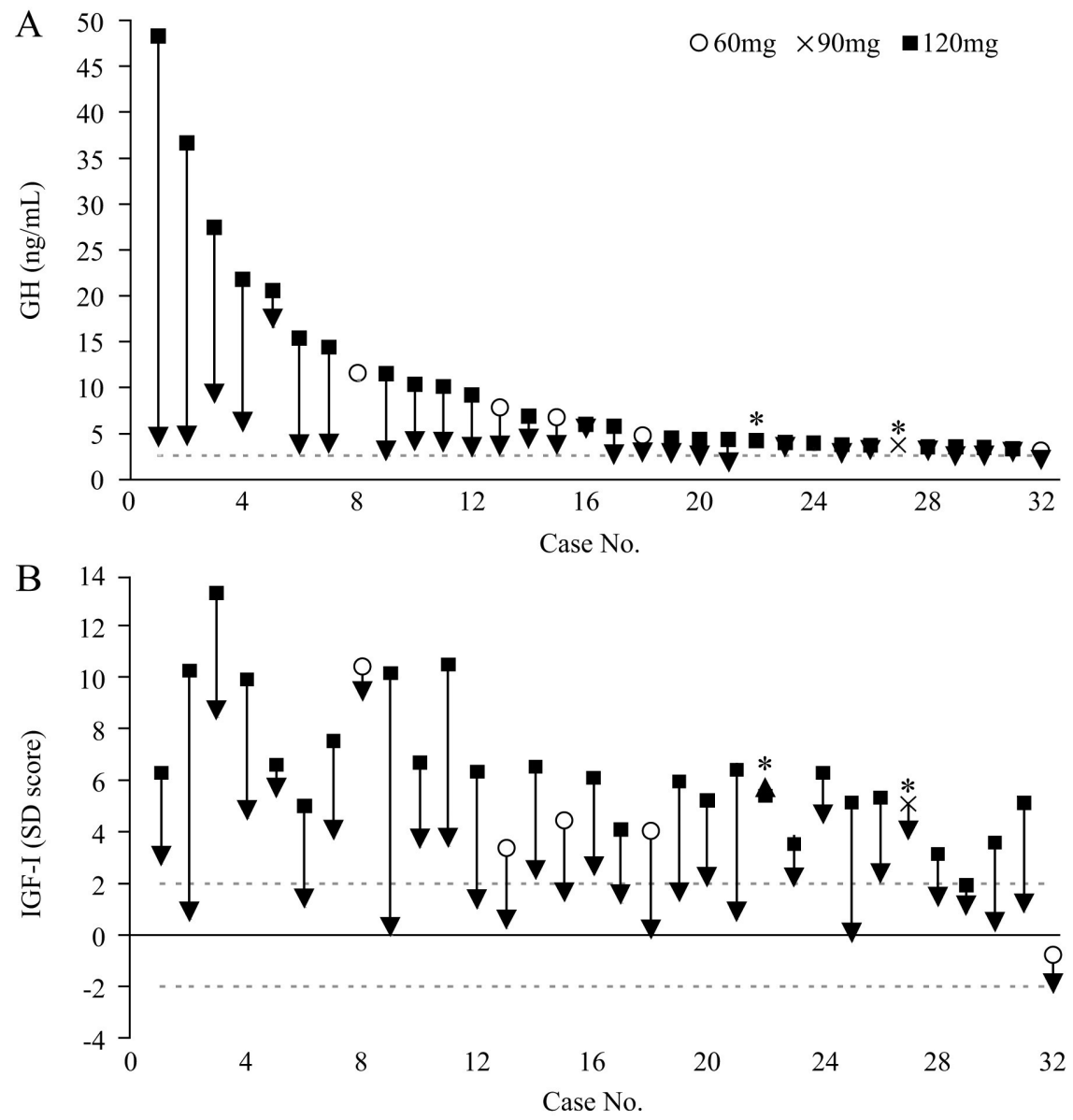

Fig. 5 Changes in (A) serum GH level and (B) SD score for IGF-I level in individual patients in the long-term study

The doses indicated are the final doses of lanreotide Autogel. Dashed line in panel A indicates the serum GH level of $2.5 \mathrm{ng} /$ $\mathrm{mL}$. Dashed lines in panel B indicate +2SD and -2SD score. Patients with an asterisk withdrew from the study. The order of patients is the same in Panel A and B. IGF-I, insulin-like growth factor-I

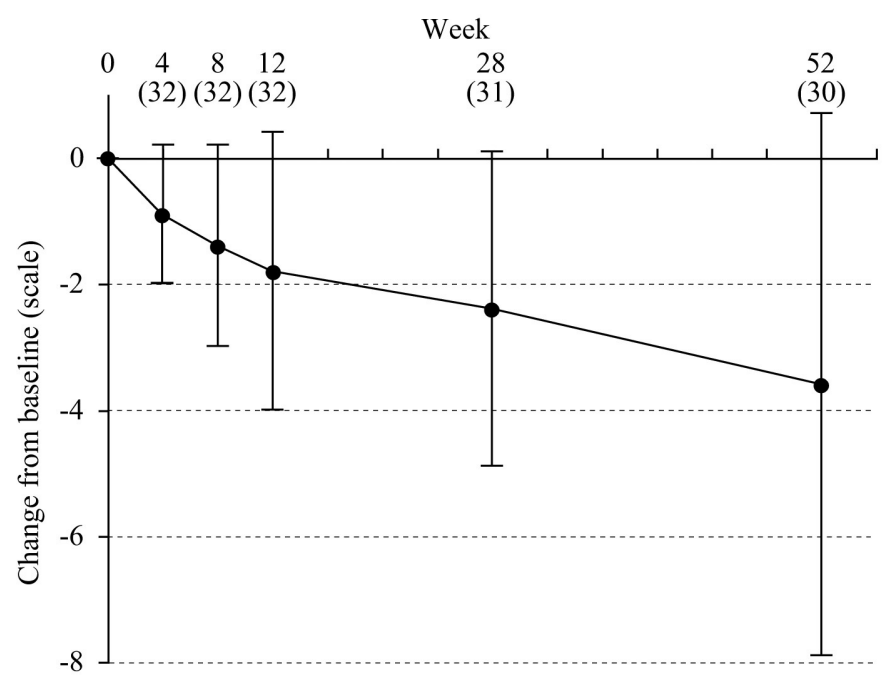

Fig. 6 Changes from baseline in the ring size of finger throughout the long-term study Parentheses indicate the number of patients. Data are presented as mean \pm SD. 
of patients $(27 / 30)$ had $\geq 1$ scale reduction in ring size at Week 52.

\section{Pituitary tumor size}

Out of 31 patients, 24 patients were evaluable for pituitary tumor size at Week 28 , and 22 patients were evaluable at Week 52. At Week 28, $2(8 \%)$ showed a reduction of $\geq 50 \%$ from baseline, $6(25 \%)$ showed a reduction of $\geq 30 \%$ to $<50 \%, 14(58 \%)$ showed no change, and $2(8 \%)$ showed an increase. At Week 52, 3 (14\%) showed a reduction of $\geq 50 \%$ from baseline, $4(18 \%)$ showed a reduction of $\geq 30 \%$ to $<50 \%, 15$ (68\%) showed no change, and no patients showed an increase. Most patients remained within the same category regarding change in tumor size at Weeks 28 and 52; the exceptions were 1 patient with no change in pituitary size at Week 52 (previously, $\geq 30 \%$ to $<50 \%$ reduction at Week 28), 1 patient with a reduction of $\geq 50 \%$ (previously with no change), and 1 patient with no change (previously with an increase).

\section{3) Safety}

During the study period, 417 AEs were observed in $30 / 32$ patients (94\%). Of these AEs, 325 were mild (28 patients, $88 \%$ ), 91 were moderate (24 patients, $75 \%$ ), and 1 was severe (1 patient, $3 \%$ ). The most commonly reported AEs were diarrhea, nasopharyngitis, injection site induration, cholelithiasis, pale feces, alopecia, upper abdominal pain, and headache (Table 2). No deaths occurred in the study. One patient (3\%) experienced 2 serious AEs after the final injection of the study drug, upper abdominal pain and pancreatic cancer. Only the upper abdominal pain was considered by the investigator to be possibly related to the study medication; pancreatic cancer was not considered related to study medication based on the clinical course of the disease. Two patients $(6 \%)$ were withdrawn due to an $\mathrm{AE}$ (abnormal hepatic function) and exacerbation of the underlying disease or absence of response to the study drug (pituitary enlargement). The AEs of malaise, alopecia, and decreased platelet count necessitated temporary withdrawal of the study drug, but patients continued in the study.

During the study period, newly developed gallstones were observed by abdominal ultrasonography in 1 out of 27 patients (4\%), and gallbladder sludge was observed in 5 out of 28 patients (18\%). Glycosylated hemoglobin (HbA1c) (JDS) concentrations increased from $5.6( \pm 0.8) \%$ at baseline to $5.9( \pm 0.7) \%$ at Week 52. An increase in HbAlc, and impaired glucose toler- ance were each observed in 3 out of 32 patients (9\%). One patient who had been treated with hypoglycemic drugs experienced hypoglycemia during the study $(3 \%)$. Two patients $(6 \%)$ tested positive for anti-lanreotide antibodies during the study (ID rates, $31-41 \%$ and $31-44 \%$ ), but not when tested at Week 52 . In these patients, serum GH and IGF-I levels were reduced throughout the study. There were no clinically meaningful changes in other safety assessments.

\section{Discussion}

The present dose-response study and subsequent long-term study in Japanese patients with acromegaly or pituitary gigantism have clearly indicated a sustained control of GH and IGF-I levels associated with the administration of sustained-release lanreotide formulation every 4 weeks.

PK data indicated that the mean serum lanreotide concentrations increased as the dose increased, and that steady-state concentrations were achieved after 4 injections. In the dose-response study, the proportion of patients exhibiting decreases from baseline in mean GH levels that were $>50 \%$ at Week 24 was $64 \%, 90 \%$, and $100 \%$ in the $60-\mathrm{mg}$, $90-\mathrm{mg}$, and $120-\mathrm{mg}$ group, respectively. In the long-term study, mean serum GH and IGF-I levels decreased through to Week 28 and remained stable through to Week 52. The proportion of patients with a $>50 \%$ reduction in mean serum GH levels and also with normalized serum IGF-I levels at Week 52 were $66 \%$ and $53 \%$, respectively. These results were consistent with those from a 52 -week international study of similar design conducted with lanreotide Autogel in non-Japanese patients diagnosed with acromegaly [9]. In the dose-response study, the proportion of patients with mean serum GH levels of $<2.5 \mathrm{ng} / \mathrm{mL}$ in the 120 -mg group was lower than the proportions in 60-mg and 90-mg group. This finding may be attributable to the causal bias in determining the baseline mean serum GH levels $(11.8 \mathrm{ng} / \mathrm{mL}, 10.8$ $\mathrm{ng} / \mathrm{mL}$, and $26.4 \mathrm{ng} / \mathrm{mL}$, respectively) in the $60-\mathrm{mg}$, 90-mg, and 120-mg group.

We did not compare the effect of lanreotide Autogel and octreotide LAR in the present study. However, findings of head-to-head comparison of both drugs were recently published, and they revealed that both the drugs had similar efficacy in terms of biochemical cure and tumor shrinkage in acromegaly patients who had undergone non-curative surgery [16]. Our findings 
Table 2 AEs occurring in $>5 \%$ of patients by preferred term (MedDRA) in the long-term study

\begin{tabular}{|c|c|c|}
\hline $\begin{array}{l}\text { System organ class } \\
\text { Preferred term } \\
\end{array}$ & Number $(\%)$ of patients & Number of events \\
\hline \multicolumn{3}{|l|}{ Gastrointestinal disorders } \\
\hline Diarrhea & $17(53)$ & 46 \\
\hline Feces pale & $10(31)$ & 25 \\
\hline Abdominal pain upper & $5(16)$ & 10 \\
\hline Abdominal pain & $3(9)$ & 6 \\
\hline Dental caries & $3(9)$ & 3 \\
\hline Flatulence & $3(9)$ & 4 \\
\hline Vomiting & $3(9)$ & 3 \\
\hline Abdominal discomfort & $2(6)$ & 6 \\
\hline Abdominal distension & $2(6)$ & 17 \\
\hline Abdominal pain lower & $2(6)$ & 5 \\
\hline Feces hard & $2(6)$ & 2 \\
\hline Nausea & $2(6)$ & 2 \\
\hline \multicolumn{3}{|l|}{ General disorders and administration site conditions } \\
\hline Injection site induration & $11(34)$ & 65 \\
\hline Injection site pain & $4(13)$ & 8 \\
\hline Injection site pruritus & $4(13)$ & 9 \\
\hline Malaise & $4(13)$ & 5 \\
\hline Chest pain & $2(6)$ & 2 \\
\hline Feeling abnormal & $2(6)$ & 2 \\
\hline \multicolumn{3}{|l|}{ Hepatobiliary disorders } \\
\hline Cholelithiasis & $11(34)$ & 13 \\
\hline Hepatic cyst & $2(6)$ & 2 \\
\hline Hepatic function abnormal & $2(6)$ & 2 \\
\hline \multicolumn{3}{|l|}{ Infections and infestations } \\
\hline Nasopharyngitis & $14(44)$ & 31 \\
\hline \multicolumn{3}{|l|}{ Investigations } \\
\hline Glycosylated hemoglobin increased & $3(9)$ & 3 \\
\hline Alanine aminotransferase increased & $2(6)$ & 2 \\
\hline Blood amylase increased & $2(6)$ & 2 \\
\hline Blood thyroid stimulating hormone decreased & $2(6)$ & 2 \\
\hline White blood cell count increased & $2(6)$ & 2 \\
\hline \multicolumn{3}{|l|}{ Metabolism and nutrition disorders } \\
\hline Glucose tolerance impaired & $3(9)$ & 3 \\
\hline \multicolumn{3}{|l|}{ Musculoskeletal and connective tissue disorders } \\
\hline Arthralgia & $3(9)$ & 6 \\
\hline Musculoskeletal pain & $3(9)$ & 4 \\
\hline Back pain & $2(6)$ & 2 \\
\hline Neck pain & $2(6)$ & 2 \\
\hline Pain in extremity & $2(6)$ & 2 \\
\hline \multicolumn{3}{|l|}{ Nervous system disorders } \\
\hline Headache & $5(16)$ & 15 \\
\hline Dizziness & $3(9)$ & 3 \\
\hline \multicolumn{3}{|l|}{ Respiratory, thoracic, and mediastinal disorders } \\
\hline Upper respiratory tract inflammation & $3(9)$ & 3 \\
\hline Cough & $2(6)$ & 2 \\
\hline Oropharyngeal pain & $2(6)$ & 3 \\
\hline \multicolumn{3}{|l|}{ Skin and subcutaneous tissue disorders } \\
\hline Alopecia & $5(16)$ & 5 \\
\hline Erythema & $2(6)$ & 2 \\
\hline Urticaria & $2(6)$ & 10 \\
\hline
\end{tabular}

Data are from the safety population $(\mathrm{N}=32)$.

MedDRA (Ver. 13.1), Medical Dictionary for Regulatory Activities Terminology 
are similar to those of a study on octreotide LAR in Japanese patients with acromegaly [19]. Sub-analysis results stratified according to the presence or absence of prior treatment with octreotide and dopamine agonist showed similar efficacy of lanreotide Autogel regardless of the type of pretreatments.

We enrolled 3 patients with pituitary gigantism in the dose-response and 2 patients in the long-term study. The responses of serum GH and IGF-I levels to lanreotide Autogel were generally similar to those in patients with acromegaly, confirming the efficacy of the drug for patients with pituitary gigantism, although the sample size was small.

It is noteworthy that the data on tumor shrinkage during lanreotide Autogel treatment were determined by central assessment of pituitary size. In the doseresponse study, 10 out of 19 evaluable patients (53\%) showed rapid and significant tumor shrinkage at Week 24 . However, in the long-term study, 8 out of 24 evaluable patients (33\%) and 7 out of 22 evaluable patients (32\%) showed tumor shrinkage at Week 28 and Week 52 , respectively. The difference in response rates for shrinkage may be explained by the higher proportion of patients who were either treatment-naive or who had not been treated within the previous 12 weeks in the dose-response study compared with the long-term study $(59 \%$ vs. 38\%). These results are consistent with a previous report demonstrating that tumor shrinkage was more frequent in treatment-naive patients than in those previously treated with radiotherapy, surgery, or drugs other than lanreotide [20].

The device used in the long-term study was a readyto-use, pre-filled syringe that does not require reconstitution facilitating injection of the full dose and has the benefit of an automatic needle safety guard that enhances safety during administration of the injection.

Lanreotide Autogel treatment was generally well tolerated. This is reflected in the proportion of patients who remained at the end of these studies. All patients completed the dose-response study, and 30 out of 32 patients completed the long-term study. Gastrointestinal and injection-site AEs were most commonly reported. There was no evidence of a dose-dependent increase in the incidence of AEs. Overall, the AE profile was as expected for SSA treatment, based on observations from clinical studies conducted previously in other parts of the world [9-13]. In the long-term study, 2 patients were withdrawn due to an AE (abnormal hepatic function) and exacerbation of the underlying disease or absence of response to the study drug (pituitary enlargement), in which drug relationships could not be ruled out. Abdominal ultrasonography performed as an additional test to assess abnormal hepatic function and mild elevation in gamma-glutamyl transferase $(\gamma-\mathrm{GT})$ level $(52 \mathrm{U} / \mathrm{L})$ prior to the start of dosing indicated hepatic steatosis. Two patients showed malaise, alopecia, and decreased platelet count, which necessitated temporary withdrawal of the study drug. Both these patients refused 1 injection of the study drug; however, their serum GH levels showed no increase during the withdrawal of lanreotide Autogel. In the cases of malaise and alopecia, it was believed to have occurred in association with normalization of GH and IGF-I levels. Based on the safety profile observed in the present studies, it may be recommended to undertake regular abdominal ultrasonography and close monitoring of blood glucose, especially in patients associated with diabetes mellitus. Three patients in the present studies tested positive for anti-lanreotide antibodies. In these 3 patients, however, expression of antibodies did not affect the treatment efficacy, and there were no adverse drug reactions, such as hypersensitivity, attributable to the presence of antibodies.

The results from the present studies are consistent with those from other trials with lanreotide Autogel in non-Japanese patients with acromegaly. However, the present studies were limited by the open-label design, and also the lack of comparator treatment arms, both of which may have influenced the results.

In conclusion, lanreotide Autogel, administered subcutaneously once every 4 weeks, was effective in controlling elevated GH and IGF-I levels and improving clinical symptoms in Japanese patients with acromegaly or pituitary gigantism. Treatment was associated with rapid onset of action and sustained efficacy over the course of the 52-week study period. Lanreotide Autogel was well tolerated, with a safety profile that was expected for an SSA.

\section{Acknowledgments}

The authors thank the patients and following doctors who acted as principal investigators at the sites of the dose-response study or long-term study; Narihito Yoshioka and So Nagai (Hokkaido University Hospital), Toshihiro Suda and Takeshi Nigawara (Hirosaki University School of Medicine \& Hospital), Fumitoshi Sato (Tohoku University Hospital), Tsuyoshi Watanabe 
(Fukushima Medical University Hospital), Masatomo Mori (Gunma University Hospital), San-e Ishikawa (Saitama Medical Center Jichi Medical University), Hideki Katakami (Teikyo University Chiba Medical Center), Ichiro Tatsuno (Chiba University Hospital), Shozo Yamada (Toranomon Hospital), Takumi Abe (Showa University Hospital), Kazue Takano (Tokyo Women's Medical University Hospital), Shigeyuki Tahara (Nippon Medical School), Koji Takano (The University of Tokyo Hospital), Yukio Hirata and Hajime Izumiyama (Tokyo Medical and Dental University, University Hospital of Medicine), Yutaka Oki (Hamamatsu University School of Medicine, University Hospital), Hiroshi Arima (Nagoya University Hospital), Michio Otsuki and Youichi Saitoh (Osaka University Hospital), Soji Kasayama (Nissay Hospital), Norio Arita (Hyogo College of Medicine Hospital), Yutaka Takahashi (Kobe University Hospital), Atsushi Tominaga (Hiroshima University Hospital), Yasumasa Iwasaki and Mitsuru Nishiyama (Kochi Medical School Hospital), Toshihiko Yanase and Masatoshi Nomura (Kyushu University Hospital), and Kazunori Arita (Kagoshima University Medical and Dental Hospital).

\section{Funding Support}

These clinical studies were sponsored by Teijin Pharma Limited. The sponsor did not impose any restrictions, directly or indirectly, on the publication of the study results. Editorial support was provided at an early stage by Chris Deakin (and funded by the study sponsor).

\section{Role of the Sponsor}

In collaboration with the authors, Teijin Pharma was involved in the study design, data collection, data analysis, and preparation of the manuscript. All authors had full access to the data upon request. The authors accept direct responsibility for the content and for the decision to submit for publication.

\section{Conflict of Interest}

AS, AT, NH and KC have served on advisory boards of these studies for Teijin Pharma. KK is employed by Teijin Pharma.

\section{References}

1. Melmed S (2006) Medical progress: acromegaly. $N$ Engl J Med 355: 2558-2573.

2. Colao A, Ferone D, Marzullo P, Lombardi G (2004) Systemic complications of acromegaly: epidemiology, pathogenesis, and management. Endocr Rev 25: 102152.

3. Alexander L, Applenton D, Hall R, Ross WM, Wilkinson R (1980) Epidemiology of acromegaly in the Newcastle region. Clin Endocrinol (Oxf) 12: 71-79.

4. Bates AS, Van't Hoff W, Jones JM, Clayton RN (1993) An audit of outcome of treatment in acromegaly. $Q J$ Med 86: 293-299.

5. Holdaway IM, Rajasoorya C (1999) Epidemiology of acromegaly. Pituitary 2: 29-41.

6. Rajasoorya C, Holdaway IM, Wrightson P, Scott DJ, Ibbertson HK (1994) Determinants of clinical outcome and survival in acromegaly. Clin Endocrinol (Oxf) 41: 95-102.

7. Melmed S, Colao A, Barkan M, Molitch A, Grossman $\mathrm{AB}$, et al. (2009) Guidelines for acromegaly management: an update. J Clin Endocrinol Metab 94: 15091517.

8. Ciccarelli A, Daly A, Beckers A (2004) Lanreotide Autoge $l^{\circledR}$ for acromegaly: A new addition to the treatment armamentarium. Treat Endocrinol 3: 77-81.
9. Melmed S, Cook D, Schopohl J, Goth MI, Lam KSL, et al. (2010) Rapid and sustained reduction of serum growth hormone and insulin-like growth factor-1 in patients with acromegaly receiving lanreotide Autogel ${ }^{\circledR}$ therapy: a randomized, placebo-controlled, multicenter study with a 52 week open extension. Pituitary 13: 18-28.

10. Caron P, Beckers A, Cullen DR, Goth MI, Gutt B, et al. (2002) Efficacy of the new long-acting formulation of lanreotide (lanreotide Autogel) in the management of acromegaly. J Clin Endocrinol Metab 87: 99-104.

11. Caron P, Bex M, Cullen DR, Feldt-Rasmussen U, Alfonso AMP, et al. (2004) One-year follow-up of patients with acromegaly treated with fixed or titrated doses of lanreotide Autogel. Clin Endocrinol (Oxf) 60: 734-740.

12. Caron P, Cogne M, Raingeard I, Bex-Bachellerie V, Kuhn JM (2006) Effectiveness and tolerability of 3-year lanreotide Autogel treatment in patients with acromegaly. Clin Endocrinol (Oxf) 64: 209-214.

13. Chanson P, Borson-Chazot F, Kuhn JM, Blumberg J, Maisonobe P, et al. (2008) Control of IGF-I levels with titrated dosing of lanreotide Autogel over 48 weeks in patients with acromegaly. Clin Endocrinol (Oxf) 69: 299-305. 
14. Croxtall JD, Scott LJ (2008) Lanreotide Autogel ${ }^{\circledR}$ : A review of its use in the management of acromegaly. Drugs 68: 711-723.

15. Murray RD, Melmed S (2008) A critical analysis of clinically available somatostatin analog formulations for therapy of acromegaly. J Clin Endocrinol Metab 93: 2957-2968.

16. Tutuncu Y, Berker D, Isik S, Ozuguz U, Akbaba G, et al. (2012) Comparison of octreotide LAR and lanreotide autogel as post-operative medical treatment in acromegaly. Pituitary 15: 398-404.

17. Research Study Group on the Hypothalamo-Pituitary Dysfunction, the Ministry of Health, Labor and Welfare, Japan. Guidelines for the diagnosis and treatment of acromegaly and pituitary gigantism. Available at: http:// rhhd.info/pdf/001001.pdf Accessed Dec 25, 2012 (In Japanese).

18. Shimatsu A, Fujieda K, Hanew K, Tanaka T, Yokoya S, et al. (1996) Clinical evaluation of serum IGF-I, IGF-II and IGFBP-3 measured by IRMA kits in adulthood. Horumon to Rinsho 44: 1129-1138 (In Japanese).

19. Oki Y, Inoue T, Imura M, Tanaka T, Genma R, et al. (2009) Investigation into the efficacy and safety of octreotide LAR in Japanese patients with acromegaly: Shizuoka study. Endocr J 56: 1095-1101.

20. Mazziotti G, Giustina A (2010) Effects of lanreotide SR and Autogel on tumor mass in patients with acromegaly: a systematic review. Pituitary 13: 60-67. 